\title{
Gender Equlity at the Davos Forum: Economic Participation and Justice
}

\author{
Ana Luiza da Gama e Souza \\ Estácio de Sá University, Rio de Janeiro, Brazil \\ Lara Denise Góes da Costa \\ Brazilian War College, Rio de Janeiro, Brazil
}

\begin{abstract}
This paper analyzes gender equality from the point of view of the World Economic Forum (WEF) and the Davos Forum, based on the results published in the Gender Gap Report 2017. First, the Davos Forum will be presented as a relevant global non-state actor, and its proposal to measure the gap gender among 144 nations. In second place, we analyzed data on gender equality, especially regarding economic participation and access to opportunities. Finally, we will point to some viable demands for justice in the private space.
\end{abstract}

Keywords: gender gap; World Economic Forum; global justice

\section{Tha Gap Gender According to World Economic Forum}

Data from the latest World Economic Forum (WEF) Global Gender Report ${ }^{1}$ show that the global labour force participation declines and this decline has been particularly accentuated for women. In terms of income, earned incomes have been increasing, but this upward trend has been steeper for men than for women. Therefore, according to the report, the growth in prosperity is not equitably distributed along gender lines. Putting in perspective the position that women occupy in the corporate structure, only $22 \%$ of individuals holding senior managerial positions are women.

The demands of gender equality today are being updated to the new global configuration and in terms of rights, it means adding to the local perspective the global economic context, in which the State is inserted. Economic globalization has transformed the world politically and brought enormous challenges to the realization of human rights. This process, because of the combination of several factors, shifted the center of state power to the economy, from the public space to the private space, and this structural translation profoundly impacted the ideal of realizing human rights, since the ideal of change social relationship focused on the human person necessarily passes through the material conditions of existence for the realization of citizenship.

\footnotetext{
Ana Luiza da Gama e Souza, Ph.D. in Philosophy, associate professor, Law Department, Estácio de Sá University, Rio de Janeiro, Brazil.

Lara Denise Góes da Costa, Ph.D. in Sociology, adjunct professor, Political theory Department, Brazilian War College, Rio de Janeiro, Brazil.

${ }^{1} \mathrm{http} / / /$ www3.weforum.org/docs/WEF_GGGR_2017.pdf.
} 


\section{The Davos Forum and the Economicus Women}

The World Economic Forum is the institutional representative of global ${ }^{2}$ economic power. It calls itself an independent and for-profit international organization; a private space for deliberation on public space, which has gained public identity and power to influence the global public sphere, with proposals aimed at emerging markets, such as Brazil—nations with low social and human development. The FEM defines itself as a global community made up of multiple strategic partners-initially 1,000 founding companies-that attaches responsibility to the global civil society, its clients, governments, and other sectors that it deems relevant for success in achieving its goals. It calls itself a public service organization, and in this role, it is committed to "improving the conditions of the world" by making informed decisions.

The new economic configuration, according to WEF reports, is deeply compatible with the policies and practices of neoliberalism, since it seeks to reproduce market logic via an idealistic feminist subjectivity, such as "rational economic woman" or "Davos woman". This new shift in the market view aimed at the economic, that is, competitive, rational, and self-interested woman emerges as a discourse for those or those who are socially considered more capable of developing economic growth in the neoliberal molds.

This simplistic perspective, in representing women in this way, disguises not only the burdens of marriage, children, and family, in which women are still the greatest contributor in terms of dedication, but also deepens inequality and recognition, since the conditions for such are far from being fulfilled socially. For Elias (2013), it would be essential to clarify the conditions for improving the economic growth of developing countries that allow new market opportunities for women. As well as explaining that the non-appropriation of a WEF Gender Agenda refers to broader processes of capitalist transformation, in which organizations advocate neoliberal policies that make it possible to increase their legitimacy as global actors without seeking inclusive gender solutions. It would therefore be appropriate to think about the forms of gender engagement for global social justice and how specific gender policies can contribute to the competitiveness of the economy and growth. This gender discourse constitutes a form of depoliticized analysis that does not elucidate how gender inequalities function within contemporary processes of capitalist expansion. In the political sphere, this process has resulted in the weakening of the State's role, especially in the protection and improvement of human rights.

The relationship between economic development and enhancement of human rights is not simply a cause and effect relationship. If the modern economy was thought of as a means for human progress and development, the market economy reversed this logic. The mechanisms of the market economy have their own purpose: to ensure greater profitability with a stimulus to competitiveness within and beyond the state, notwithstanding the disastrous consequences for human development, due to the worsening of social inequalities.

In addition, the post-feminist discourse operated in the WEF is based on deeply gendered understandings that force the world's women to identify with innate skills or general characteristics, ignoring intersectional ties, to grant certain groups of women (such as those who participate in Davos gatherings) privileged status in the current global order. This perspective also serves to mask the many benefits that corporations enjoy with forms of gender inequality, since it is ultimately an act of regime maintenance that "universalizes", denying differences.

In the view of Amartya Sen (2000) and the empowerment of a person depends on a set of factors, including the characteristics peculiar to the people, but above all, the social context in which it is inserted. And

${ }^{2}$ Retirado de http://www3.weforum.org/docs/WEF_InstitutionalBrochure.pdf 
that is why deprivations are evaluated from a political and social perspective of deprivation, since empowerment is measured by the set of real opportunities that the person has in their favor. The quality of life and therefore the life worthy of a human being should not be understood only as a mere set of goods and services, but of the actual opportunities available to the people.

The gender equality discourse of the WEF therefore becomes part of the discursive arsenal and techniques that aim at the production of adequately neoliberal subjectivities as "enabled" to be consumers and with that, become an instrument within the logic of the market, in reproducing its economic maintenance and its capitalist assumptions. As Bourdieu (2002) had shown, to reproduce the agents is to reproduce the categories that organize the world, as well as their schemes of perception.

Sen's (2000) demand is still sharply focused on the state but addressing inequalities and success in protecting and realizing human rights shifts to global space. The global interconnections brought about by the global market economy reduce the power of the state to control activities within and outside its territory, and furthermore, the expansion of transnational forces and interactions reduces and restricts the influence that governments have on the activity of their (Held, 1991, p. 158).

\section{Global Gap Gender End Global Justice}

If justice as citizenship can be understood in moral terms, in which equal distribution would mean compromising with an ideal of universal justice, that is, encompassing all, in the recognition bias the social differences would be tied to the quality of life, that is, to the freedom that each one must have to live according to the highest social level available. In this sense, economic distribution and social recognition are intertwined in cultural and social policies of economic equality.

Nancy Fraser (2007) had already articulated the sphere of recognition as a presupposition of difference and the status sphere, in which the demands for a better quality of life combine both the socioeconomic sphere and the cultural sphere. Thus, for Fraser, there would be two types of claims for social justice: redistributive claims, which seek a fairer distribution of resources and wealth, and thus translate the economic-social aspect of the issue, and claims for recognition, in which the goal it would be a world that amiably welcomed the differences.

However, the model of "identity", although politically relevant, would tend to reify identities into groups, promoting separatism and repressive communitarianism, insofar as it establishes a cultural identity that would be fluid due to the great currents of cultural communication of the days current. In this respect, Fraser (2007) demonstrated that initially the claims for recognition and redistribution were in opposition. While proponents of recognition seek their foundation from the achievement of a good life, in which values would be given according to the context and particular differences, those of redistribution would be based on norms of justice that would be universally binding and would remain the involvement of the particularities of the agents. Fraser (2007) considered this false antinomy and seeks to argue that the two approaches have points in common and can be understood together.

Facing the theoretical confrontation that the philosopher points out and the problematic practices of social reality, Fraser (2007) elaborated a third possibility for the realization of both claims. Social justice must be thought of in the socio-economic sense of redistribution and cultural recognition or of the difference in the sense of equality. Fraser's strategy to break the pattern of recognition is to try to understand the claims of one cultural group within another dominant. In a society where rights exist for one group and not for another, the 
identity of the unrecognized group occurs through denial of rights. Cultural patterns thus reveal the relative position of social actors and the ability to participate in conditions of equality or inequality with others. When all cultural patterns are recognized in a way that allows equal participation, we can speak in reciprocal recognition and equality.

When, on the contrary, institutionalized patterns of cultural value constitute some actors as inferior, excluded, or unable to participate fully in social interaction or in terms of access to better opportunities, then we have an inappropriate recognition and subordination of status. In addition to discrimination, non-realization of equal rights for all causes low self-esteem and inhumanity, obscuring social interaction and hindering recognition. Thus, non-recognition does not mean depreciation and deformation of group identity but social subordination in the sense that inappropriately recognized individuals are prevented from participating as equals $^{3}$ in social life.

In this context, what is expected of minority recognition is the possibility of self-affirmation as a group, through the real participation of minority members in the majority group in equitable ways. This results in a status of parity participation, in the sense that its culture materializes and enables rights.

Recognition being a question of status, it can be inferred that a particular society in which there is social subordination by some group is an unjust society, provided that one group does not have conditions to participate in that society on the same level as others. Recognition as status, therefore must be understood from the examination of institutionalized cultural values that prevent the interaction and enjoyment of the rights of one group for the sake of another. The demands for recognition would serve as a form of delegitimation of these values as naturalized. The status model for Fraser also has another benefit, which is the fluidity of the concept of status compared to that of identity.

While identity would require a specific group recognition policy, which would materialize culture in a fixed way and ignore contemporary cultural crossings, the status model would relate equality as a level playing field, that is, parity of participation would provide a deontological model compatible with democratic politics, without being fixed to a specific value, provided that this model is in agreement with a certain culture.

For Nancy Fraser, to say that some individuals are restricted by certain groups for reasons of cultural differences or non-recognition in general, it is to disparage the particular and distinctive characteristics of these individuals by subordinating them to certain cultural patterns institutionalized by the other part of the population. Thus, the lack of recognition is given as something wrong, since it constitutes a form of violation of justice.

Following this perspective, we come to the conclusion that living a good life holds the subjectivist theoretical presupposition of the one who formulates it, that is, the conception of a good life would be a subjective understanding, and with each cultural perspective, there is always the hypothesis of confrontation of value, that is, of different conceptions of good, which would make recognition unfeasible. In the case of recognition based on a deontological foundation, the ideal of justice is linked to the social segment as a whole and not in certain groups. Starting from the idea of a society that holds different conceptions of good and good life, to be a fair society is to provide possibilities so that all can enjoy their own conception of good.

Examination of institutionalized patterns of cultural value aims to reveal social agreements or

\footnotetext{
${ }^{3}$ Here, Fraser gets to the point he wants to defend. The universality which the concept of justice in the line of morality presupposes must be interpreted according to the category of status, that is, to the extent that all can participate in a society equally and enjoy equal rights. The condition is therefore the possibility of exercising rights equally.
} 
disagreements that impede participation, that is, equal conditions in access to assets and rights of all members of society. The discussion of rights, as well as the principles that underlie them, became the stage of theoretical controversies that aimed at practical solutions to conflicts between cultures and social inequalities in broader scenarios. The expansion of the market beyond national borders was one of the ingredients that allowed the transition from a mercantilist economy to a mercantile capitalism and from there to a self-regulating and global system. In the contemporary era, the commitment was strong, practical, and theoretical, or vice versa-for the development of a market economy, whose bases would be in the idea of economic freedom. For neoliberal theorists, the space of economics is the space of freedom, not interference by the state.

From the social and economic inequality that in the mercantilist modernity was provoked by an economy as a monopoly of the public space, we pass nowadays to a monopoly of the economy by the private space and that has been deepening and spreading the inequalities. The impact of the transnationalization of the economy, through global corporations, has serious implications for the socioeconomic reality of the States, since these companies: "progressively uprooted themselves, planning and realizing their activities in terms of their own geo-economics, often unrelated to the peculiarities or idiosyncrasies of national governments" (Ianni, 1999, p. 190).

Given the impact of the market in the state reality, we can see how it diminishes its capacity to contain and effect crucial aspects of citizenship. Marshall (1967, pp. 61-64) problematized, centered on England in the 1950 s, the contrast between capitalism and inequality, arguing that citizenship would be a legitimate claim for the individual to be admitted as a participant within a particular social heritage, would mean acceptance as a full member of a given society. For the authors, inequality in the class system would be mitigated by the status of citizenship, when equality can be recognized.

The construction of laissez-faire did not seek equality of conditions, but freedom to build itself economically as a citizen, that is, only autonomy to enter the economic struggle, which in a way prevented a possible claim for any legal protection of the state or social benefit in this sense. In view of the above, citizenship can be directly related to people's quality of life through the realization of their rights. Socio-economic vulnerabilities translate an abyss that separates who is a citizen from who is not; hierarchizing people according to the enjoyment of their rights and these can be understood as privileges, since they are not universalized.

The process of development of the global market economy is identified with the premises of economic liberalism, which presupposes that it is the faculty of the economic individual or "Homo economicus" to choose among several alternatives opened by the market (Priban 1983, p. 618). Economic freedom thus means competitiveness and in this logic the freedom of a competitor is limited only by the same measure of freedom as other competitors. But how to compete in unequal conditions?

As Fraser (2005a) had shown, the "weakness of social democracy" within the internal states under pressure in global neoliberalism coincided with the demands of feminism in the orbit of identity. In this sense, feminist political-economic deployments were not only neglected, they also conversed intimately with the new transnational political configuration.

\section{Conclusion}

The process of economic globalization has put human rights in check as envisioned by the Declaration of 48. First, by worsening social and economic inequalities, mitigating the indivisible character of human rights 
with the depletion of basic social rights and as a consequence of economic vulnerability-social, the vulnerability of civil, and political rights. Second, because of the weakening of the state, the obligations of human rights are addressed.

The World Economic Forum would, in theory, have the role of representing the interests of civil society today. However, because of its apolitical character, its influence calls into question social development and inequalities, which makes its debate in the sphere of Human rights. The goals for effective citizenship in the new context of a globalized economy are still open. The extension of this concept from the new world reality can allow a new look at the limits and possibilities of discussion of the Forum as a public sphere, generating greater democratic inclusion and, consequently, a wider range of social inequalities and human development.

\section{References}

Bourdieu, P. (2002). A dominação masculina: A condição feminina e a violência simbólica. Bestbolso.

Elias, J. (2013). Davos woman to the rescue of global capitalism: Postfeminist politics and competitiveness promotion at the World Economic Forum. International Political Sociology, 7, 152-169.

Fraser, N. (2007). Recognition without ethics? Theory, Culture \& Society 2001. London, Thousand Oaks and New Delhi: SAGE.

Fraser, N. (2007a). Mapping the feminist imagination: From redistribution to recognition to representation. Revista Estudos

Feministas, 15(2).

Glover, J. (1996). Women, culture, and development: A study of human capabilities. Oxford: Oxford University Press.

Held, D. (1990). A democracia, o estado-nação e o sistema global. In Lua Nova No. 23. Work presented at the Conference “Aprofundando e Globalizando a Democrarcia”, 17-22 de março de, Japan.

Ianni, O. (1998). Globalização e neoliberalismo. São Paulo em Perspectiva, 12(2).

Marshall, T. H. (1967).Cidadania, classe social e status. Rio de Janeiro: Zahar Editors.

Nussbaum, M., \& Sen, A. (1993). The quality of life. Oxford: Oxford University Press.

Pigman, G. A. (2007). The world economic forum: A multi-stakeholder approach to global governance. London: Routledge.

Priban, K. (1983). A history of economic reason. London: The Johns Hopkins University Press.

Sen, A. (2000). Development as freedom (Reprint edition). Anchor. 